\title{
JNM

\section{Disaccharidase Deficiency as a Cause of Unexplained Functional Gastrointestinal Disorder}

\author{
Yong Hwan Kwon ${ }^{1,2}$ \\ ${ }^{1}$ Department of Internal Medicine, School of Medicine, Kyungpook National University, Daegu, Korea; and ${ }^{2}$ Kyungpook National University \\ Hospital, Daegu, Korea
}

\begin{abstract}
Article: Prevalence of disaccharidase deficiency in adults with unexplained gastrointestinal symptoms Viswanathan L, Rao SS, Kennedy K, Sharma A, Yan Y, Jimenez E

(J Neurogastroenterol Motil 2020;26:384-390)
\end{abstract}

During the past decades, carbohydrate digestion and absorption have been extensively investigated. Carbohydrates are hydrophilic, and several reactions are required to digest them into monosaccharides that can be absorbed in the small intestine. Carbohydrates are broken down into monosaccharides by various enzymes, including disaccharidases. Disaccharidases are protected from proteolysis by glycosylation and comprise of maltases, sucrases, and lactases, which are present in the brush border of the small intestinal wall. ${ }^{1}$

A congenital or acquired deficiency of these enzymes results in an excess of carbohydrate substrate in the small bowel, which increases the osmotic load, leading to an increase in luminal fluid. Excessive fermentable substrate also increases gas production in the small bowel, leading to small bowel distension. ${ }^{2,3}$ This condition may result in the feeling of early satiety, bloating sensation in functional dyspepsia and irritable bowel syndrome patients, and abdominal pain, especially in patients with visceral hypersensitivity. ${ }^{4-6}$ However, if such enzyme deficiencies are underdiagnosed, they could represent a neglected cause of functional gastrointestinal disorder (FGID) and unnecessarily prolonged symptoms. Moreover, due to the high frequency of these symptoms, disaccharidase deficiency may be misdiagnosed as food allergy or intolerance. Thus, accurate diagnosis of disaccharidase deficiency is particularly important in functional gastrointestinal motility disorders. Although these enzyme deficiencies have been reported in children, there is a lack of evidence from studies of adults.

In this regard, Viswanathan et $\mathrm{al}^{7}$ reported that lactase deficiency was the most common enzyme deficiency, with a prevalence of $35.8 \%$, and pan-disaccharidase deficiency $(9.2 \%)$ was the second most common disaccharidase deficiency based on evaluation of small bowel biopsies from 120 adults. However, the prevalence and severity of 11 gastrointestinal symptoms did not differ between normal individuals and individuals with single enzyme deficiency. Generally, the Rome IV criteria characterize FGIDs by symptomatology to make the diagnosis easier for clinicians, and diagnoses of FGIDs are usually established without evaluation of carbohydrate digestion; hence, symptoms in cases of functional gastrointestinal disorders and carbohydrate intolerance can be confused easily.

This suggests that patients presenting with gastrointestinal symptoms affected by variations in diet should be suspected of having disaccharidase enzyme deficiency, and testing should be consid-

Received: June 10, 2020 Revised: None Accepted: June 12, 2020

(c) This is an Open Access article distributed under the terms of the Creative Commons Attribution Non-Commercial License (http://creativecommons. org/licenses/by-nc/4.0) which permits unrestricted non-commercial use, distribution, and reproduction in any medium, provided the original work is properly cited.

*Correspondence: Yong Hwan Kwon, MD Internal Medicine, Kyungpook National University Medical School Hospital, 807, Hogukno, Buk-gu, Daegu 41404, Korea Tel: +82-53-200-3081, Fax:+82-53-200-3089, E-mail: tear9754006@yahoo.co.kr 
ered in certain clinical situations.

Various methods are available for diagnosing disaccharidase deficiency, including endoscopic biopsy, breath tests, genetic tests, and even an oral trial of various formulations of the enzyme. To our knowledge, the "gold-standard" to achieving a definitive diagnosis is small bowel biopsy, especially a biopsy of the proximal portion of the intestine - just distal to the duodenum. For accurate diagnosis of disaccharidase deficiencies, at least 2 biopsies are obtained. One biopsy for analysis of the "architecture" of the intestine is to confirm whether the mucosal pattern is normal or not. The other biopsy is taken to determine whether enzymes are at normal levels. However, enzyme deficiencies may be patchy and could be missed by biopsy, and so it may be less cost-effective compared with breath tests. ${ }^{8,9}$ Still, while the breath test is a non-invasive test option, it may not enable proper distinction between the different types of enzyme intolerance, and the breath test may be falsely positive in patients with small intestinal bacterial overgrowth. ${ }^{10}$

Developing treatment strategies using disaccharidase replacements is challenging due to the limited information available. A randomized study showed that patients who received sacrosidase or sacrosidase plus milk had significantly decreased breath $\mathrm{H}_{2}$ excretion when compared with placebo, and individuals receiving higher concentrations of sacrosidase were observed to exhibit fewer FGID symptoms. ${ }^{11}$ However, because of limited sample sizes and selection bias in previous studies, there is insufficient evidence that treatment with enzyme replacement will improve symptoms.

Taken together, disaccharidase deficiencies should be considered and evaluated in patients presenting with FGID symptoms. To investigate the incidence and clinical manifestations of these enzyme deficiencies in FGID patients, larger cohort studies are required. Furthermore, it would be needed to develop a protocol to determine which subset of patients with ostensibly functional disorders should be tested and subsequently treated.

\section{Financial support: None.}

\section{Conflicts of interest: None.}

\section{References}

1. Kiela PR, Ghishan FK. Physiology of intestinal absorption and secretion. Best Pract Res Clin Gastroenterol 2016;30:145-159.

2. Vernia P, Ricciardi MR, Frandina C, Bilotta T, Frieri G. Lactose malabsorption and irritable bowel syndrome. Effect of a long-term lactose-free diet. Ital J Gastroenterol 1995;27:117-121.

3. Goldstein R, Braverman D, Stankiewicz H. Carbohydrate malabsorption and the effect of dietary restriction on symptoms of irritable bowel syndrome and functional bowel complaints. Isr Med Assoc J 2000;2:583587.

4. Tolliver BA, Jackson MS, Jackson KL, Barnett ED, Chastang JF, DiPalma JA. Does lactose maldigestion really play a role in the irritable bowel? J Clin Gastroenterol 1996;23:15-17.

5. Robayo-Torres CC, Quezada-Calvillo R, Nichols BL. Disaccharide digestion: clinical and molecular aspects. Clin Gastroenterol Hepatol 2006;4:276-287.

6. Nelis GF, Vermeeren MA, Jansen W. Role of fructose-sorbitol malabsorption in the irritable bowel syndrome. Gastroenterology 1990;99:10161020.

7. Viswanathan L, Rao SS, Kennedy K, Sharma A, Yan Y, Jimenez E. Prevalence of disaccharidase deficiency in adults with unexplained gastrointestinal symptoms. J Neurogastroenterol Motil 2020;26:384-390.

8. Cohen SA, Oloyede H, Gold BD, Mohammed A, Elser HE. Clinical characteristics of disaccharidase deficiencies among children undergoing upper endoscopy. J Pediatr Gastroenterol Nutr 2018;66(suppl 3):S56S60.

9. Nichols BL Jr, Adams B, Roach CM, Ma CX, Baker SS. Frequency of sucrase deficiency in mucosal biopsies. J Pediatr Gastroenterol Nutr 2012;55(suppl 2):S28-S30.

10. Rezaie A, Buresi M, Lembo A. Hydrogen and methane-based breath testing in gastrointestinal disorders: the north American consensus. Am J Gastroenterol 2017:112:775-784.

11. Treem WR, McAdams L, Stanford L, Kastoff G, Justinich C, Hyams J. Sacrosidase therapy for congenital sucrase-isomaltase deficiency. J Pediatr Gastroenterol Nutr 1999:28;137-142. 